\title{
SISTEM INFORMASI PENGELOLAAN ASET DI SDI AL-ANSHAR
}

\author{
Bagas Wijaya ${ }^{1}$, Muhamad Nur Witama ${ }^{2}$ \\ Program Studi Teknik Informatika, Fakultas Teknik dan Ilmu Komputer, \\ Universitas Indraprasta PGRI \\ Jalan Raya Tengah No 80, Kelurahan Gedong, Pasar Rebo, Jakarta Timur \\ Bagaswijaya256@gmail.com¹, Tamarun2019@gmail.com²
}

\begin{abstract}
Abstrak
Teknologi informasi yang bergerak dalam bidang pengelolaan aset atau sistem informasi manajemen, asset merupakan salah satu sistem yang banyak digunakan oleh perusahaan termasuk sekolah. Tujuan penelitian ini adalah merancang sistem informasi pengelolaan asset pada SDI AL-Anshar Bekasi yang dapat memudahkan SDI AL-Anshar dalam pendataan/aset dan pembelian sehingga menjadi lebih cepat dan akurat. Metode yang digunakan dalam penelitian ini menggunakan metode Research and Development (R\&D). Hasil penelitian ini yaitu aplikasi pengelolaan asset yang dapat mempermudah petugas pengelola mengetahui barang aset yang dimiliki oleh sekolah dan juga dapat memberikan informasi data asset barang yang lebih akurat. Juga untuk menghindari resiko kehilangan data, karena data disimpan di database dan mudah untuk membuat salinan datanya, dan untuk merapihkan data agar lebih terstruktur dan dinamis.
\end{abstract}

Kata Kunci :Sistem Informasi, Pengelolaan Aset, Data

\begin{abstract}
Information technology which is engaged in asset management or management information systems, asset is one of the systems widely used by companies, including schools. The purpose of this study is to design an asset management information system at SDI AL-Anshar Bekasi which can facilitate SDI AL - Anshar in data collection/assets and purchases so that it becomes faster and more accurate. The method used in this study uses the Research and Development $(R \& D)$ method. The results of this study are an asset management application that can make it easier for management officers to know the assets owned by the school and can also provide more accurate information on asset data. Also to avoid the risk of data loss, because the data is stored in the database and it is easy to make copies of the data, and to organize the data to make it more structured and dynamic.
\end{abstract}

Keywords: information_systems, asset_management, data

\section{PENDAHULUAN}

Perkembangan teknologi yang cukup pesat dari waktu ke waktu membuat pekerjaan yang dilakukan manusia pada umumnya dapat diselesaikan dengan mudah, cepat, dan efektif. Di era modern seperti ini teknologi merupakan alat bantu yang paling sering digunakkan dalam aktivitas manusia, hal ini tidak terlepas dari keterbatasan manusia sendiri. Penggunan teknologi khususnya komputer saat ini memang sangat penting dan dibutuhkan, hal ini didukung dengan semakin banyaknya para pengembang teknologi informasi yang dituntut untuk lebih kreatif dan inovatif dalam memajukan industri komputer.

Seiring berkembangnya kemajuan teknologi informasi dan komunikasi, maka dibutuhkan berbagai aplikasi yang berguna untuk memudahkan dalam menjalankan pekerjaan manusia. Setiap perusahaan, lembaga, ataupun sekolah pasti memiliki sistem aset, peran sistem ini tidak bisa dianggap sepele. Kesuksesan perusahaan, lembaga, ataupun sekolah tidak terlepas dari peran pengelolaan sistem aset yang baik. Karena dari itu perusahaan yang mampu mengendalikan dan mengelola persediaannya dengan baik akan dapat memenuhi kebutuhan pelanggan dan tentu saja dapat menjaga kelangsungan bisnisnya dalam dunia modern saat ini.

Menurut definisinya aset mengacu pada persediaan segala barang sumber daya yang digunakan dalam sebuah organisasi yang dapat berbentuk bahan mentah, pekerjaan dalam proses, barang jadi, suku cadang komponen, maupun persediaan. 
Aset barang didalam suatu usaha menjadi hal penting bagi suatu perusahaan, lembagam ataupun sekolah, karena dari aset terbesut bisa mengelola stok barang digudang yang nantinya akan dijual ke konsumen ataupun diganti dengan yang baru. Oleh karena itu pihak pengusaha atau pemilik tersebut harus dapat mengelola aset barang dengan efektif dan efesien agar sesuai dengan tujuan dan berjalan baik.

SDI AL-Anshar merupakan sebuah sekolah pada era modern, yang harus dituntut untuk membrikan pelayanan, pendidikan, dan kemandirian bagi para siswanya. Tak terlepas dari itu, sekolah ini juga terus berusaha mengembangkan metode pembelajaran dan sistematika dalam mengurus dan mengelola berbagai sistemnya. Pada proses pengolahan data sistem aset di SDI AL-Anshar yang masih belum menggunakkan sistem yang terkomputerisasi, dalam pendataan stok aset masih dilakukan secara manual dengan mencatat sebuah buku tulis ataupun laporan sementara.

Berdasarkan pada permasalahan diatas peneliti bermaksud membuat penelitian dengan judul "Sistem Informasi Pengelolaaan Aset Di SDI AL-Anshar Tahun 2019". Dengan tujuan adanya sistem aset barang dapat memudahkan SDI AL-Anshar dalam pendataan/aset dan pembelian sehingga menjadi lebih cepat dan akurat.

\section{PENELITIAN RELEVAN}

Dalam rangka mendapatkan hasil penelitian yang baik, selain melakukan penelitian secara langsung peneliti juga melakukan kajian pustaka. Dari hasil penelitian yang telah dilakukan. Beberapa hasil acuan yang menjadi acuan adalah:

Penelitian dari Ahmad Baihaki, tahun 2016 berjudul "Aplikasi Sistem Inventori dan Penjualan Pada Cano Digital Print Depok". Merancang dan membuat sistem monitorinng penjualan digital printing pada Cano Digital Print yang efektif dan efesien agar memperoleh data yang akurat, tepat dan cepat.

Penelitian dari Patrecia Natalia, tahun 2016 berjudul "Sistem Inventori Barang Pada Koperasi Kartika Berbasis Java". Merancang sistem pengelolaan data yang akan dibuat pada koperasi sehingga dihasilkan program aplikasi yang efektif dalam pengelolaan data.

Penelitian dari Stefanus Susetyawan, tahun 2018 berjudul "Perancangan Sistem Informasi Inventori Berbasis Java Netbeans Pada SMK Ganesa Satria 1 Depok". Mempermudah petugas SMK Ganesa Satria 1 Depok untuk mengetahui data barang inventori yang dimiliki serta memberikan informasi data inventori barang yang lebih akurat.

Perbedaan penelitian yang dibuat oleh peneliti dengan penelitian dari Ahmad Baihaki tahun 2016 yang berjudul "Aplikasi Sistem Inventori dan Penjualan Pada Cano Digital Print Depok" yaitu tidak ada sistem penjualan di penelitian yang peneliti buat.

Penelitian dari Patrecia Natalia tahun 2016 yang berjudul "Sistem Inventori Barang Pada Koperasi Kartika Berbasis Java" tidak ada sistem penambahan stok barang otomatis saat admin menambahkan barang baru, jumlah stok barangnya masih di rubah secara manual. Sedangkan di penelitian yang dibuat oleh peneliti sudah mampunyai sistem penambahan stok barang otomatis saat admin menambahkan barang baru.

Kemudian penelitian dari Stefanus Susetyawan tahun 2018 yang berjudul "Perancangan Sistem Informasi Inventori Berbasis Java Netbeans Pada SMK Ganesa Satria 1 Depok" tidak ada menu "Info Barang" yang menjelaskan nama barang, bahan, brand, kondisi barang, jumlah barang serta lokasi barang dimana barang itu berada. Sedangkan di penelitian yang dibuat oleh peneliti sudah mampunyai sistem tersebut.

\section{METODE PENELITIAN}

Dalam penelitian ini peneliti menggunakan penelitian Research and Development (R\&D). Menurut (Sugiyono, 2012) metode penelitian Research and Development yang selanjutnya akan disingkat menjadi R\&D adalah metode penelitian yang digunakan untuk menghasilkan produk tertentu, dan keefektifan produk tersebut. Produk tersebut selalu berbentuk benda atau perangkat keras (hardware), seperti buku, alat tulis, dan alat pembelajaran lainnya. Akan tetapi dapat pula dalam bentuk perangkat lunak (software). 
1. Metode Pengumpulan Data

Dalam mengumpulkan data, keterangan dan rancangan program yang dibutuhkan untuk Sistem Informasi Pengelolaan Aset di SDI AL - Anshar Tahun 2019, peneliti menggunakan 2 (dua) metode yaitu:

a. Metode Observasi

Pengertian Observasi adalah metode atau cara-cara yang menganalisis dan mengadakan pencatatan secara sistematis mengenai tingkah laku dengan melihat atau mengamati individual atau kelompok secara langsung.

b. Metode Wawancara

Suatu cara pengumpulan data yang digunakan untuk memperoleh informasi langsung dari sumbernya. Wawancara dilakukan secara lisan dalam pertemuan tatap muka secara individu.

\section{HASIL DAN PEMBAHASAN}

Berdasarkan Identifikasi Masalah di SDI AL-Anshar Bekasi ini masih menerapkan sistem yang manual seperti :

1. Proses pencatatan data barang/aset dan pembelian serta barang yang harus diganti masih menggunakan sistem sederhana.

2. Proses pembuatan laporan memakan waktu yang cukup lama dan masih berupa pembukuan arsip.

3. Informasi mengenai transaksi pembelian kebutuhan sekolah belum akurat.

4. Sistem informasi yang belum terkontrol dengan baik sehingga mempengaruhi sistem lain.

Penerapan aplikasi pengelolaan aset pada SDI AL-Anshar Bekasi dan Berikut ini merupakan penggambaran tentang metode yang digunakan pada Sistem Informasi Pengelolaan Aset di SDI AL Anshar Bekasi.

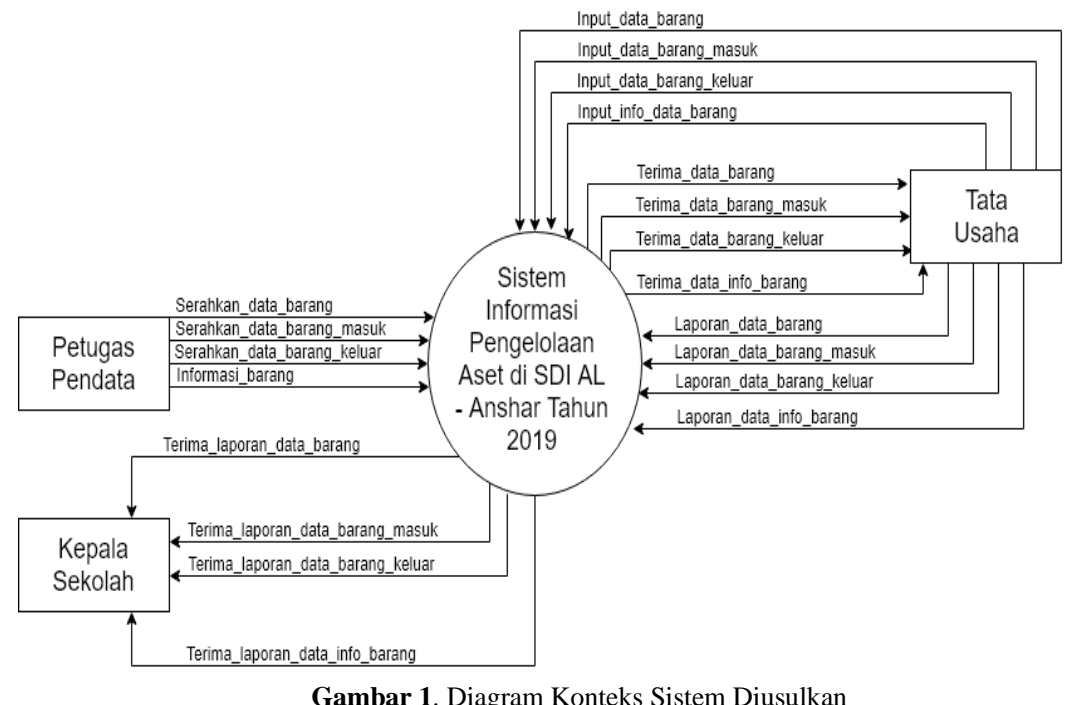

Gambar diatas adalah Diagram Konteks Sistem Diusulkan yang menjelaskan tentang tahapan proses secara keseluruhan dan garis besar. 


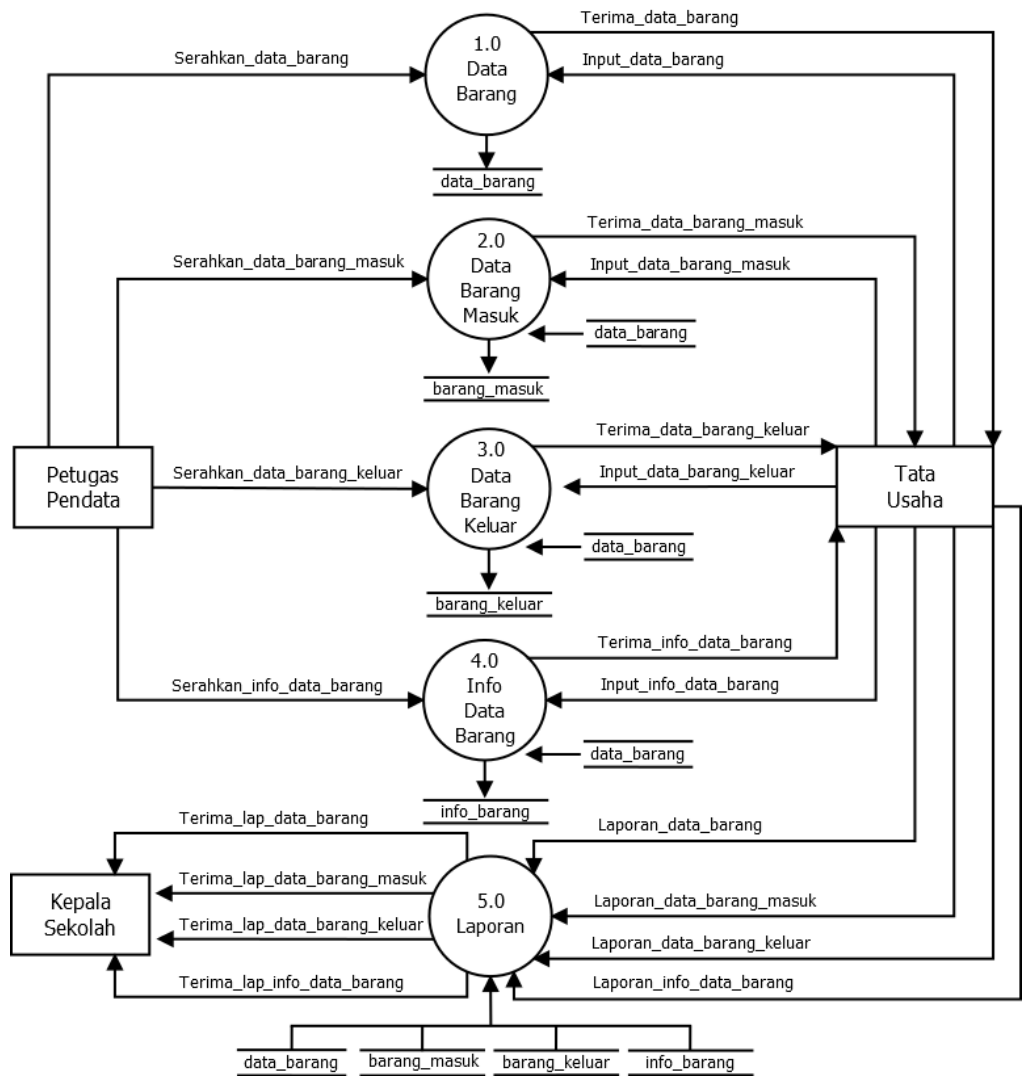

Gambar 2. Diagram Nol Sistem Diusulkan

Gambar diatas adalah Diagram Nol Sistem Diusulkan yang menjelaskan tentang detail tahapan disetiap proses beserta dengan database nya.

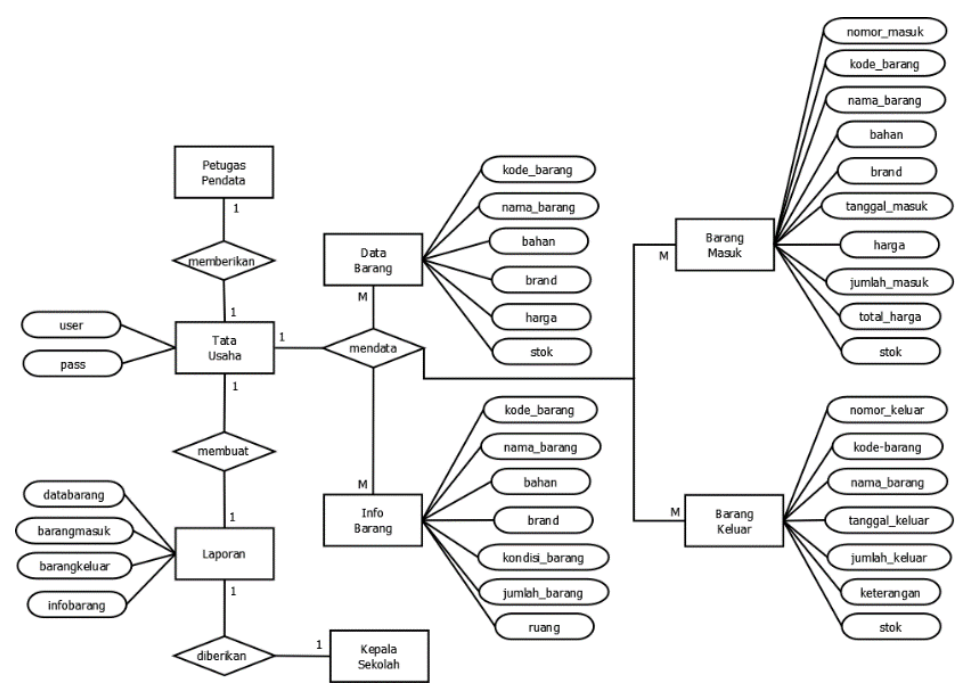

Gambar 3. ERD (Entity Relationship Diagram) Diusulkan

Gambar diatas adalah ERD (Entity Relationship Diagram) yang menjelaskan tentang alur proses dan relasi disetiap tabelnya. 


\section{Tampilan Layar Aplikasi}

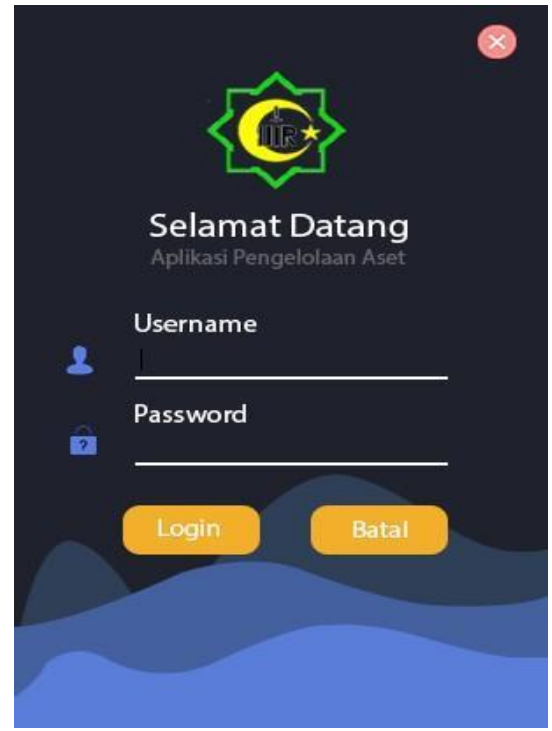

Gambar 4. Tampilan Login

Tampian Login muncul diawal saat pengoperasian program sistem informasi aset untuk diisi oleh tata usaha sebagai user. Masukkan username dan password supaya bisa mengoperasikan sistem informasi aset. Jika username dan password sesuai, maka selanjutnya akan muncul tampilan Menu Utama.

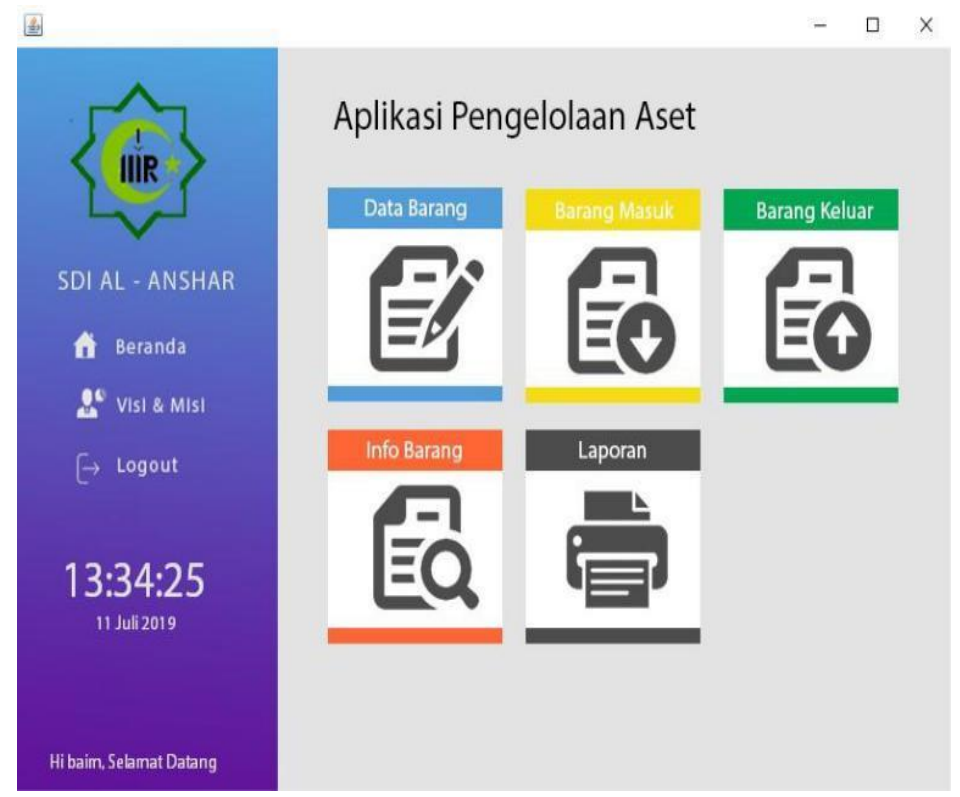

Gambar 5. Tampilan Menu Utama

Tampilan Menu Utama ini terdapat beberapa bar menu yang akan menampilkan form - form masukkan data, dan keluaran data. 


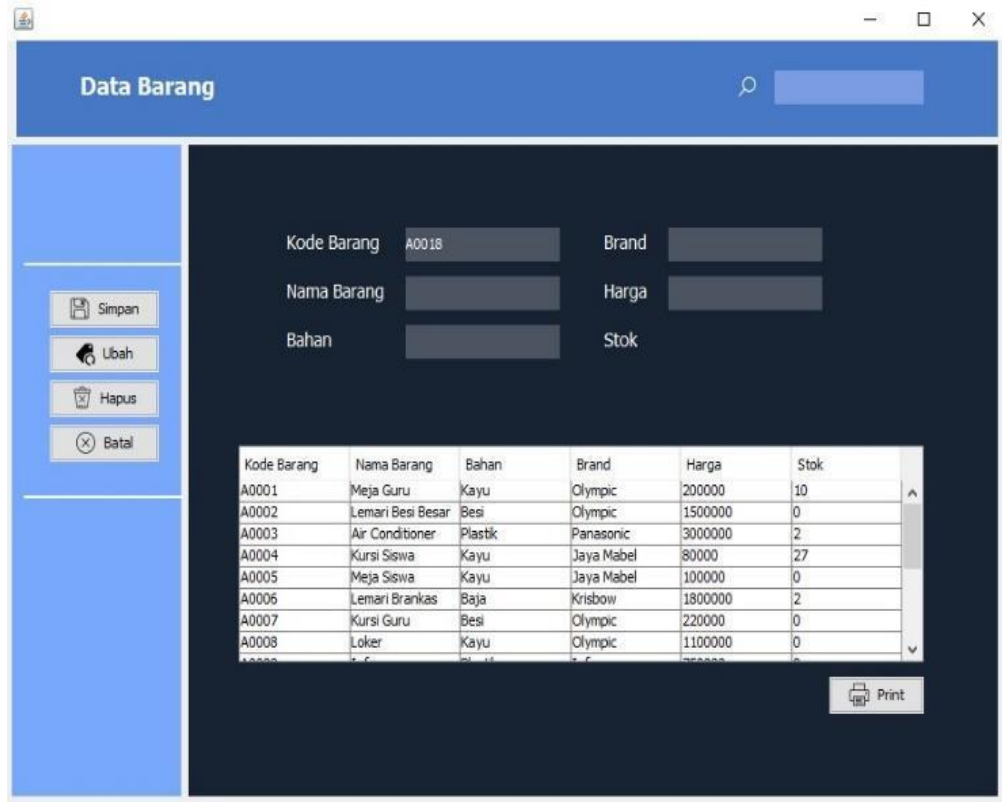

Gambar 6. Tampilan Form Data Barang

Tampilan form data barang, user dapat melakukan penambahan data barang dengan mengklik tombol (simpan), untuk mengubah atau memperbarui data klik tombol (ubah), untuk menghapus data klik tombol (hapus), untuk mencetak laporan hasil input-an klik tombol (cetak).

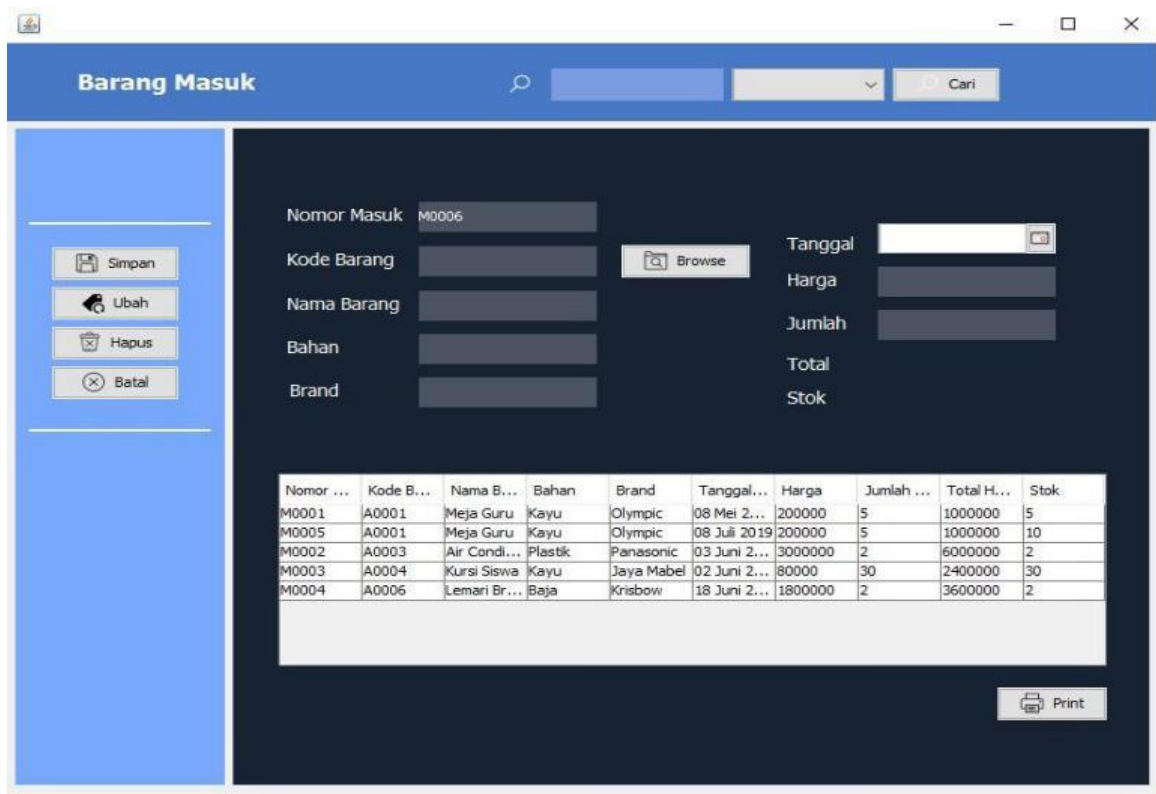

Gambar 7. Tampilan Form Barang Masuk

Tampilan form barang masuk, user dapat melakukan penambahan data barang dengan mengklik tombol (simpan), untuk mengambil atau memanggil data barang dengan mengklik tombol (browse), untuk mengubah atau memperbarui data klik tombol (ubah), untuk menghapus data klik tombol (hapus), untuk mencetak laporan hasil input-an klik tombol (cetak). 


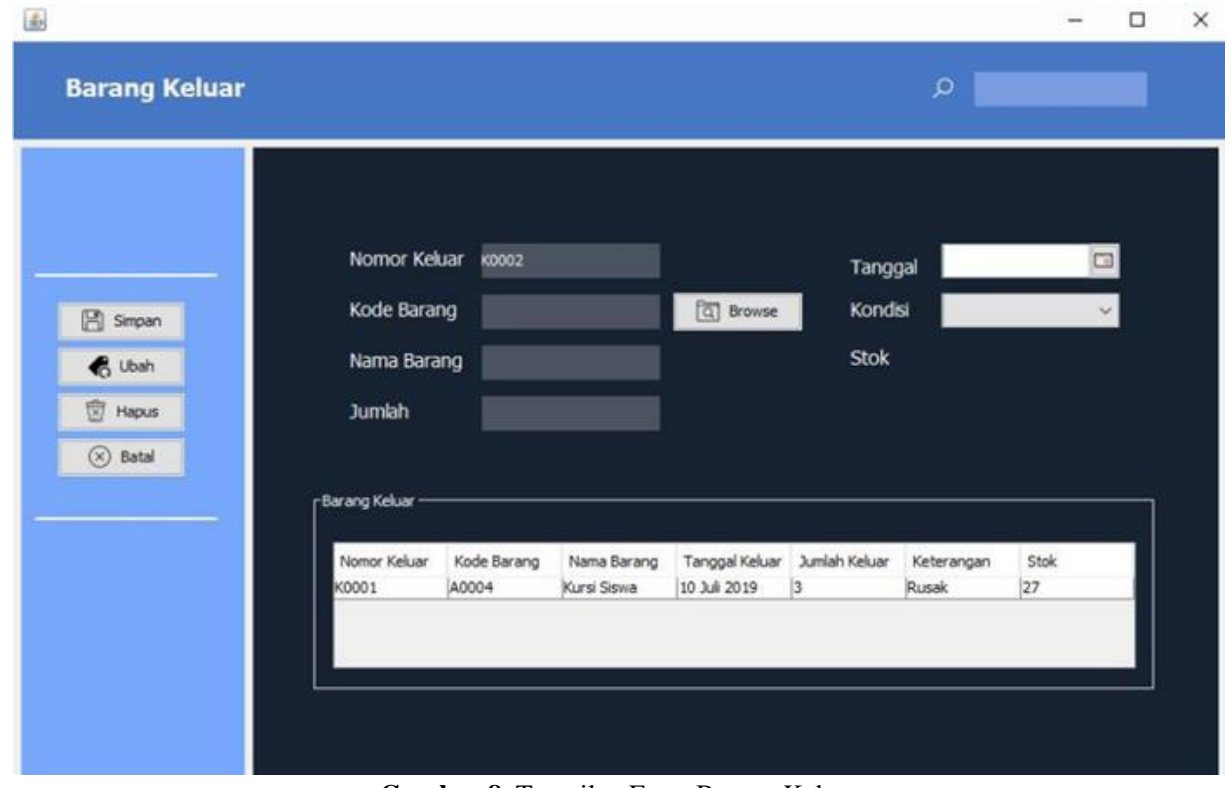

Gambar 8. Tampilan Form Barang Keluar

Tampilan form barang keluar, user dapat melakukan penambahan data barang dengan mengklik tombol (simpan), untuk mengambil atau memanggil data barang dengan mengklik tombol (browse), untuk mengubah atau memperbarui data klik tombol (ubah), untuk menghapus data klik tombol (hapus), untuk mencetak laporan hasil input-an klik tombol (cetak).

\section{SIMPULAN}

Berdasarkan pembahasan yang telah dilakukan, maka dapat diambil beberapa kesimpulan, diantaranya sebagai berikut :

1. Sistem informasi aset yang sedang berjalan di SDI AL-Anshar Bekasi masih dilakukan pengelolaan data operasional perpustakaan secara sederhana dan manual. Proses pengelolaan dan pendataan yang dilakukan diantaranya pendataan data barang, barang masuk, barang keluar, informasi barang, dan pembuatan laporan - laporan. Sistem aplikasi yang digunakan saat ini hanya menggunakan aplikasi Microsoft Office dan pembukuan secara manual.

2. Sistem informasi aset yang diusulkan untuk SDI AL-Anshar Bekasi menggunakan proses pendataan dan pembuatan laporan yang di tunjang dengan adanya aplikasi aset ini dapat dilakukan dengan lebih efektif dan efesien, sehingga proses tersebut tidak akan mamakan waktu yang lama dan memperkecil kemungkinan hilangnya data - data penting yang disebabkan oleh rusak atau hilangnya dokumen pendataan. Informasi seluruh barang yang tersedia di sekolah menjadi mudah dicari dan diketahui dengan cepat, karena petugas dapat mencari barang dengan otomatis tanpa harus mencari ulang ke ruangan - ruangan sekolah. Penyajian berbagai bentuk laporan dari bagian aset yang sudah dilakukan secara otomatis tentu akan memudahkan dalam menyampaikan informasi kepada pihak sekolah.

\section{DAFTAR PUSTAKA}

Anhar. (2010). PHP \& MySql Secara Otodidak - Google Buku. In Mediakita.

Dvorski, D. D. (2007). Installing, configuring, and developing with Xampp. D. Dvorski Dalibor.

Fatoni, A., Dwi, D., NS, S., Sutabri, T., Subandi, Syahidi, A. A., Hayadi, B. H., Rukun, K., S, R. A., Shalahuddin, M., Muslihudin, M., Oktafianto, Mardiani, E., Rahmansyah, N., Kurniawan, H., Muliawati, A., Permana, D. S., Hutahaean, J., Huda, M., Setiawan, E. B. (2018). Java Fundamental Dengan Netbeans 8.02. In Jurnal Teknologi Informasi Komunikasi Pendidikan.

Indrajani. (2018). Database Design All in One - Theory, Practice, and Case Study. In Buku Database. Jeperson Hutahean. (2015). Konsep Sistem Informasi - Jeperson Hutahaean - Google Buku. In Agustus.

Maniah; Hamidin, D. (2017). Analisis Dan Perancangan Sistem. Universitas Widya Mandala Madiun.

Muhammad Muslihidin, \& Oktafianto. (2016). Analisis dan Perancangan Sistem Informasi Menggunakan Model Terstruktur dan UML. In Jurnal Teknik Informatika Politeknik Sekayu (TIPS).

Pamungkas, C. A. (2017). Pengantar dan Implementasi Basis Data. In Pengantar dan Implementasi Basis Data. 
Salhazan. (2014). Sistem Manajemen Basis Data, Yogyakarta. Universitas Stuttgart.

Sugiyono. (2012). Metode Penelitian Kuantitatif, Kualitatif dan R \& D.Bandung:Alfabeta. Metode Penelitian Kuantitatif, Kualitatif Dan R \& D.Bandung:Alfabeta. https://doi.org/10.1017/CBO9781107415324.004

Supriyono, H., Noviandri, A. M., \& Purnomo, Y. E. (2017). Penerapan Sistem Informasi Berbasis Komputer Untuk Pengelolaan Aset Bagi SMP Muhammadiyah 1 Kartasura. The 6th University Research Colloquium 2017.

Sutabri, T. (2012). Analisis Sistem Informasi. In Analisa Sistem Informasi. 